\title{
Construction and Research of National Cross - regional Supply Chain Network Based on New Silk Road
}

\author{
Jingjing Shi, Jianze Zhou \\ (Xidian University, Xi'an, Shaanxi 710071; Xidian University, Xi'an, Shaanxi 710071)
}

\begin{abstract}
China put forward the concept of "Silk Road Economic Belt" is a strategic initiative of cooperation with a global vision. "Silk Road Economic Belt" provides a good opportunity to strengthen economic and cultural exchanges with the countries along the line, open up the international market, the development of foreign trade, For the development of domestic industries to provide a broader market space. So pay attention to the advantages of regional cooperation, from the cross-regional supply chain to start, concerned about the economic cooperation between China and Asian and European countries, regional integration in the product, logistics and capital advantages, improve the optimal allocation of resources. In this paper, the Silk Road economic belt as the main line, along the country as a node to discuss the establishment of cross-regional supply chain. Analyze the advantages of each node, and study how to strengthen the optimization of the whole supply chain, and how to make the flow of information flow, logistics and capital flow fast, so as to accelerate the circulation of the whole supply chain,. So as to obtain the actual boosting effect of the supply chain on the economic development of each country.
\end{abstract}

Keywords: cross-regional supply chain; Silk Road economic belt; Economic Cooperation

\section{Introduction}

The Silk Road was once one of the greatest supply chains in history. It links China and Central Asia and Central Asia to Europe and promotes the economic and trade development, culture and customs exchange between these regions and countries. And the Asian and European countries to build the Silk Road economic belt. Although the goal of economic and trade cooperation and development-oriented. But its strategic significance is extensive, is related to the national security issues such as national defense security, economic and trade security, energy security, frontier security and other important areas of the overall situation. Has great strategic significance. In the domestic economy to build the Silk Road economic belt, will provide more opportunities for development. Promote the economic development of the zone. Narrowing the regional gap. Promote balanced economic development. On the diplomatic road to build the Silk Road economic belt can be connected to Asia and Europe to build a large land channel. Economic and trade development to promote comprehensive cooperation, efforts to deepen mutual benefit and win-win situation. Actively promote regional security cooperation, and safeguard the overall situation of peace and stability in the surrounding areas. Silk Road economic belt is not simply to reproduce the ancient Silk Road. In nature, it is a political economy, internal and external diplomacy and space-time across as one of the history beyond the version. In the content, it is set to open west and west development as one integrated policy version. In the formation, it is after several generations of collective leadership to plan national security strategy and economic strategy of the contemporary upgrade.

\section{Current Situation of Cross Regional Supply Chain Theory}

Cross-regional supply chain refers to the supply chain in the various nodes of the country, under the conditions of limited resources, in order to achieve the greatest competitive advantage, the country has its own advantages of products or services center, by a number of different sizes, Of the country's enterprises, through the information network and fast logistics system to link up, the flow of funds into the supply chain, the composition of the open form of organization. The essence of the supply chain is to play their own advantages, resources and external forces for effective integration, in order to reduce costs and improve competitiveness objectives ${ }^{[1]}$.

The research contents of supply chain theory mainly focus on supply chain coordination mechanism, supply chain integration management, operation management, information management, supply chain partner selection, inventory problem and so on.

Mary J. Meixell agreed that the supply chain management is required to the concept of globalization, the supply chain system extends to the whole world, in a comprehensive and rapid understanding of consumer demand around the world while at the same time, its planning, coordination, Operation, control and optimization of the supply chain, the core enterprises in the supply chain and their suppliers and suppliers suppliers, core enterprises and their distributors and to the final consumer, relying on modern network information technology support, to achieve supply chain integration and rapid response operation, to coordinate logistics, information flow and value flow unobstructed to meet global consumer demand ${ }^{[2]}$. Coen D discusses supply chain operations from the perspective of supply chain

Volume 6 Issue 1, January 2017 


\section{International Journal of Science and Research (IJSR) \\ ISSN (Online): 2319-7064}

Index Copernicus Value (2015): 78.96 | Impact Factor (2015): 6.391

enterprise relationships. According to the supply chain enterprises in the supply chain structure of the different positions, the relationship between the supply chain enterprises are divided into vertical and horizontal relationship between the relationship, pointing out that the same position of the enterprise horizontal or alliance relationship, such as several suppliers relationships; and in the relationship between the upstream and downstream enterprises in the supply chain, known as single-longitudinal relationships or partnerships, such as the relationship between suppliers and service providers ${ }^{[3]}$.

Ma Shihua think that the supply chain is around the core business, through the flow of information, logistics, capital flow control, starting from the procurement of raw materials, intermediate goods and the final product from the sales network to the products to consumers in the hands of suppliers, manufacturers, Distributors, retailers, until the end user into a whole functional chain structure model, supply chain management is through the feed-forward information flow and feedback of the material flow and information flow, the suppliers, manufacturers, distributors , retailers until the end-users together into a whole model ${ }^{[4]}$ Xiao Wei, Laiming Yong genre of global supply chain management theory to analyze the global supply chain research into classical studies - multinational company decision-making problems, modern research - widely used planning tool and contemporary research - the introduction of the concept of social responsibility into three categories $^{[5]}$. Liu Rong and Zhang Bixi think that supply chain management is to integrate resources advantages on a global scale, to form a rapid response capability to market demand, to meet the needs of customers with high quality and low cost operation management mode, is in the internationalization of science and education, Information network, financial integration, based on the principle of integration of global resources, supply, design, production in the most suitable location, so that mutual coordination, mutual promotion and complement each other, thus forming a seamless whole advantages ${ }^{[6] .}$ Li Peng is an example of foreign leading enterprises, analyzed the practice of supply chain management, explained the supply chain practice, the supply chain flexibility and value chain network integration importance, and introduced well-known enterprise supply chain best practices for other enterprises reference ${ }^{[7] .}$

\section{The Establishment of Cross - Regional Supply Chain}

\subsection{The initial establishment of cross-regional supply}

\section{chain}

The current supply chain is moving in the agile, green, information technology, customer-oriented, highly flexible direction. On the basis of the concept of the "Silk Road Economic Belt", the countries along the route are the nodes and the advantages of each node are analyzed. The establishment of cross-regional supply chain. The supply chain is a dynamic supply chain. Suppliers, manufacturers, distributors are a dynamic concept of relativity. We unified the raw materials, spare parts provider known as the supplier, the manufacturer of the product known as the manufacturer, the product sellers known as the distributor. A manufacturer may be referred to as a supplier, a manufacturer, and a distributor, respectively, with respect to different objects. The supply chain can be represented by a network structure model (Figure 1). The arrows in the figure indicate the direction of the supply chain, with small circles representing the nodes (The Silk Road Economic Belt States). There are links between the logistics, information flow and capital flow and other links. In theory, there is such a connection between every two nodes, but these links are strong and weak.

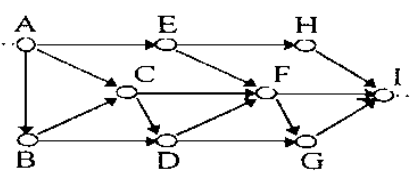

Figure 1: The mesh model of the supply chain

The goal of the cross-regional supply chain is to respond quickly to customer needs and supply chain risks, reduce product costs, increase profitability, improve customer service levels, optimize inventory, improve lead times and business processes. So that a reasonable flow of logistics in the supply chain, optimizing the configuration, thereby shortening the production cycle and reduce production costs. The supply chain also facilitates the communication, dissemination and interaction of information between enterprises on the supply chain, which is accurate, real-time and visible. It promotes cooperation among suppliers, distributors and manufacturers as well as common grasp of market opportunities.

\subsection{Advantages analysis of the Silk Road countries in the supply chain network}

As the Silk Road economic belt on the land attached to the eastern end of the development potential of the Asia-Pacific region and the eastern part of China, the middle string of resource-rich Central Asia and the development potential of western China, the west to the developed economies in Europe. This provides the possibility of establishing cross-regional supply chains.

(1) Central Asian countries have the advantage of being a supplier in the supply chain system. Central Asian countries are extremely rich in natural resources. Kazakhstan and Uzbekistan in the oil reserves and natural gas reserves in the forefront of the world. Kazakhstan at the end of 2011300 billion barrels of proven oil reserves and natural gas reserves of 1.9 trillion cubic meters, coal reserves of 33.6 billion tons ${ }^{[8]}$ Turkmenistan's oil and gas resources and the distribution of coastal and northern regions of the Caspian Sea, by the end of 2011 proven oil reserves of 24.3 trillion Cubic meters, accounting for $11.7 \%$ of the world. More than $60 \%$ of the region of Uzbekistan has oil and gas development prospects, has proven natural gas reserves of 1.6 trillion cubic meters, about 600 million barrels of oil reserves in ${ }^{[9] .}$ Tajikistan is rich in hydropower resources,

\section{Volume 6 Issue 1, January 2017




\section{International Journal of Science and Research (IJSR) \\ ISSN (Online): 2319-7064}

Index Copernicus Value (2015): 78.96 | Impact Factor (2015): 6.391

has huge almost untapped water resources, water resources, ranking No. 8 in the world, per capita in the world ${ }^{[10]}$

Metal rich in resources, wide variety. Kazakhstan has proven mineral deposits of more than 90 kinds, of which tungsten reserves in the world No. 1, silver, lead, chromium proven reserves of the world's No. 2, the world's third largest copper reserves. Uzbekistan has the fourth largest gold reserves in the world. Lead, copper, zinc and tungsten are the leading reserves in the Soviet Union, and the reserves of uranium are about 55,000 tons, ranking the eighth in the world [10]. Kyrgyzstan's mineral resources, antimony reserves of the world's No. 3, tin production and mercury production in the CIS No. 2. Gold reserves are large, there are more than 30 large and close to large-scale gold, Kumtor gold mine for the world's top ten most promising mining one of the rich. Tajikistan mining industry to non-ferrous metals and rare metals-based, mainly lead-zinc, tungsten and molybdenum ore. Kazakhstan's phosphate reserves in Asia, the first 1 Turkmenistan Karabogas Gore Bay has a wealth of chemical raw materials [10].

(2) China has the advantages of manufacturers in the supply chain system. China's manufacturing industry is rich in energy. China's Xinjiang, Gansu, Qinghai, Ningxia, Shaanxi, Sichuan and Chongqing, the use of abundant natural resources, formed a petrochemical industry, mining, non-ferrous metal processing, equipment manufacturing industry as the dominant industries, According to their respective advantages into the characteristics of agricultural and livestock products and processing industries and characteristics of tourism, and the eastern part of China mainly in the financial, transportation and other industries mainly for the western region to provide financial and technical support. China to Central Asia to provide more of the mechanical and electrical equipment, household products, so the transnational supply chain should play the advantages of China's manufacturing industry.
(3) European developed economies have the advantages of distributors in the supply chain system. Silk Road west to the developed economies in Europe, for the entire production chain to provide a broad consumer market. First, because Central Asia is rich in energy can not own consumption, will make two or more countries to participate in consumption, European countries developed economy makes it has the ability to consume, but also its economic development needs. The second is due to the rapid development of European countries, commodity economy, has a set of advanced and comprehensive sales strategy and sales system, to do the end of the supply chain links.

\section{Optimization of Logistics, Information Flow and Capital Flow}

Based on the advantages of each node country, the information flow, logistics and capital flow management can make the supply chain more efficient operation. (SupplyChainManagement SCM) is through the information flow, logistics, capital flow analysis and control, to customer demand, product development, raw material procurement, product manufacturing, product sales and product services and supply chain links and effective resources planning and control ${ }^{[11] .}$ The core of supply chain management is to transform and integrate the internal parts of the enterprise through information communication, data interchange and collaboration among the manufacturers, suppliers, distributors, retailers and end customers, through realizing the enterprises in the supply chain. And external business processes in order to achieve more efficient production, distribution, sales and service activities on the whole, reduce the turnaround time and reduce the customer response time by shortening the lead time and increasing the profitability of the enterprise. Here each country as the supply chain nodes, and each node has its internal supply chain, and each node, each node within the interrelated, intertwined, forming a network structure of the supply chain (Figure 2). 


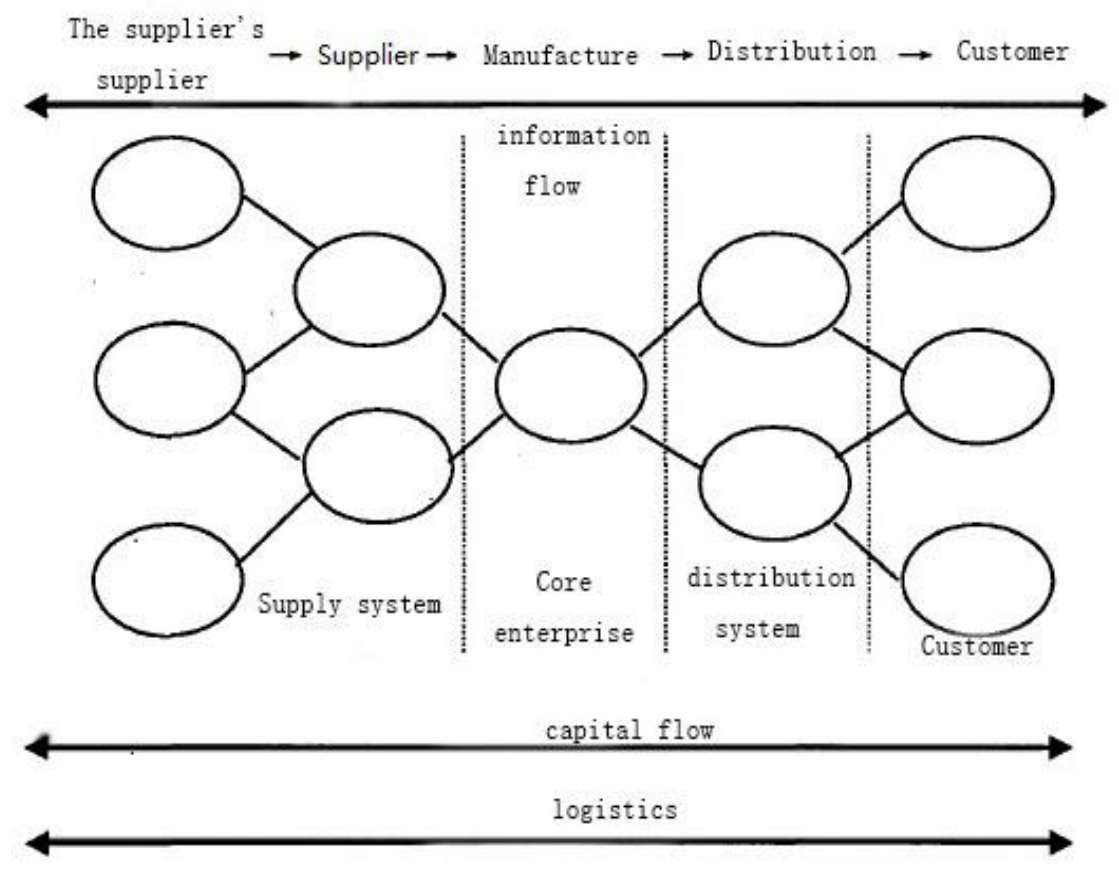

Figure 2: Network structure of the supply chain

\subsection{Construction of modern logistics service system, build logistics information platform}

Silk Road economic belt construction is the core of the economic zone to achieve coverage and radiation areas of free flow of goods and resources complement each other. Silk Road across the Eurasian continent, large geographical span, high transport costs, large shipping capacity in modern and low-cost competition, the use of land-based intercontinental economic linkages, the development of the limitations has been spanning the region National, inter-city economic development between the important obstacles. Through the construction of modern logistics service system, the use of logistics efficiency and comprehensive service cost competitive advantage, will help to change the traditional relying solely on transport infrastructure and transport services and lack of competitiveness of the development model, by exploring the Eurasian Continental Bridge Logistics organization innovation, relying on logistics,Logistics information platform and docking enterprise logistics supply chain service system, the establishment of the international logistics channel covering the area, will make the logistics service system become an important support for the development of the Silk Road economic belt industry.

Silk Road economic belt logistics information platform is the Silk Road economic belt logistics system network platform is in the Silk Road economic belt logistics industry an important infrastructure. Silk Road economic belt logistics cooperation information platform to network, electronic and information technology for the logistics industry support. Information service logistics system to minimize the Silk Road economic belt cross-regional supply chain costs and improve the Silk Road economic belt across the regional supply chain logistics utilization.

\subsection{To achieve information sharing, the establishment of basic database information system}

Because of the independence between nodes and the short-term interests of the contradictions, information sharing in the supply chain can't be automatically achieved, the need for a partnership between enterprises, or the node countries and enterprises will only be based on their different objectives And local information to make their own profits to maximize the decision-making, will not fully take into account the performance of the entire supply chain to maximize, so that the supply chain of distributed decision-making will reduce supply chain efficiency, largely less than optimal Of the supply chain efficiency. Therefore, it is necessary to resolve the conflict of interest among the independent nodes and to form a cooperative relationship among the participants in the supply chain system. It is the prerequisite to achieve high-quality information transmission and sharing among the nodes, and also to optimize the supply chain system. near optimal necessary conditions ${ }^{[12]}$.

In order to enhance the responsiveness of the cross-regional supply chain, you can design non-stock production system using Kanban management, is the largest country to achieve the sharing of information. The establishment of supply chain network information system, the establishment of basic database system. The optimization of supply chain information resources can realize better utilization of information and promote its value creation ability. 


\section{International Journal of Science and Research (IJSR) \\ ISSN (Online): 2319-7064}

Index Copernicus Value (2015): 78.96 | Impact Factor (2015): 6.391

\subsection{Supply Chain Financial Development Support for Cash Flow}

For the optimization of capital flow in the supply chain, supply chain finance can be introduced. Financial support is a necessary prerequisite for cash flow in the supply chain, and it is also a lubricant for the supply chain operation. Should continue to develop the commercial bank supply chain finance business while actively encouraging the logistics enterprises and enterprise groups to directly participate in supply chain financial services to promote the diversification of China's supply chain financial business. Efficient capital operation is critical to developing supply chain finance. A strong ability to operate the capital so that it can reduce the cost of capital at the same time, able to accumulate sufficient funds for financing services. Which in the supply chain financing business to obtain great success. Commercial Banks Should Make Full Use of Their Own Characteristics and Policy Advantages.Enterprises can rely on strategic equity financing, etc. to raise funds, improve the financial operation ability to enhance the capital strength. To provide a solid capital base for supply chain finance.

Based on the Silk Road economic belt of cross-regional supply chain, the enrichment of funds can not do without the support of countries, therefore, the Asian Development Bank and other regional financial organizations should be given appropriate financial support.

\section{Cross-Regional Supply Chain and Efficient Operation of the Relevant Cooperation and Recommendations}

Production globalization, trade globalization and financial globalization are three manifestations of economic globalization. The concept of the Silk Road Economic Belt is put forward in this context, so that the proposed cross-regional supply chain on this basis has the possibility of realization. In the large data analysis of network marketing, build first-class supply chain system, relying on, including the world's leading large data information systems, international logistics. While the integration of Internet-based logistics, information, warehousing and other resources across the regional supply chain services. Attention to capital flow, logistics, information flow of the third-rate linkage, and actively verify the authenticity of the upstream and downstream supply chain trade, and promote the supply of financial funds to run accurately. Integration of market data market, analysis of supply and demand changes in direction. Absorb all levels of management talent, unified online and offline logistics, the establishment of warehousing networks around the world, to achieve efficient and controllable supply chain.

\subsection{Development of Competitive Industries}

Industry is the important support of the rise of the Silk Road economic belt. To realize the rapid rise and sustainable development of the economic belt, it is necessary to carry out scientific and rational industrial spatial layout and planning, follow the principle of industrial layout, combine their advantages, integrate economic belt Regional and national advantages of the existing industries, strengthen industrial policy communication to the advantage of industrial cooperation as an opportunity to "five links" for the exchange and cooperation basis to achieve economic integration of the Silk Road economic belt and the "regional cooperation." Eurasian continent countries as a whole, but also the world's economic development potential of the region, to carry out economic and trade cooperation with unique advantages, through the Silk Road economic belt to connect the various parts of the Eurasian continent, the interests of different countries suture, Sharing opportunities, complement each other, not only help to promote the economic zone along the radiation area, the country's economic development, but also conducive to maintaining peace and stability in the Eurasian continent and the world economy sustainable development. But also to establish the prerequisite for cross-regional supply chain, cross-regional supply chain for the establishment of the feasibility.

\subsection{To speed up Infrastructure Construction}

Overall, the transport infrastructure in the areas along the Silk Road has improved and the air transport situation has changed considerably over the past few years. Therefore, the reliability of the airports along the countries should be increased, and the quality of air transport should be improved. , The construction of regional road networks, agriculture, tourism can take advantage of regional business opportunities in the reconstruction of roads and improve the quality of traffic in countries still need to do a lot of work. Transportation is a very important factor in the supply chain, so improve the transportation, improve logistics efficiency is extremely important.

\subsection{Improve the Tax System}

Silk Road economic belt along the overall tax situation is generally good, but in the transparency and value-added tax rebate there are many problems, the professional quality of tax personnel is not high, a number of countries lack the status of double taxation agreement. Therefore, in order to ensure the effective operation of the supply chain, the relevant countries should improve the tax system, reduce trade barriers, give the corresponding tax incentives for cooperation countries, taking into account the interests of all countries, fair and equitable foreign trade

\subsection{Enhance cultural exchanges}

From the strategic height of attention to humanities. For the long-term development of relations between China and neighboring countries to consolidate the foundation of society and public opinion, the ancient Silk Road opened up a human open equality, inclusive mutual learning, non-competitive cultural exchanges and sharing patterns. In the era of peaceful development and common prosperity, the countries along the line need to carry forward the spirit 


\section{International Journal of Science and Research (IJSR) \\ ISSN (Online): 2319-7064 \\ Index Copernicus Value (2015): 78.96 | Impact Factor (2015): 6.391}

of the Silk Road. Strengthen cultural exchanges and economic and trade cooperation, strengthen domestic and foreign media exchanges and cooperation. Through the public, civil diplomacy, cultural communication and so enhance China's cultural soft power. Strive to build the Silk Road tourism cooperation mechanism and platform. To build the Silk Road tourism corridor, to expand the central and western universities, research institutions and the Asia-Europe cooperation in education space. We will develop and nurture human resources for schools, enterprises and governments in China and other countries along the border, and establish interactive platforms for academic groups, nongovernmental think tanks and non-governmental organizations. Deepen the study of social culture of countries along the route. Thus creating a soft environment for lasting peace and prosperity for the Silk Road economic belt.

\section{References}

[1] Liu Xiaohong, but the logistics operation mode Bin, Zhang Xumei virtual supply chain[J].Journal of Chongqing University,2004

[2] Mary J. Meixell, Vidyaranya B. Gargeya Global supply chain design: A literature review and critique [M]. ElsevierLtd,2005.

[3] Coen D, Thatcher M.Network Governance and Multi-Level Delegation: European Networks of Regulatory Agencies [J].Journal of Public policy, 2008,28 (1): 49-71

[4] Ma Shihua supply chain management. Machinery Industry Press.2000.5

[5] Xiao Wei, Lai Mingyong. Schools of global supply chain management theory analysis [J].Development Review,2009,(1):107-110.

[6] Liu Rong, Zhang Bi West. Implementation of supply chain knowledge management. Value engineering.2005.2

[7] Li Peng real, Cao, animal husbandry, and so on.On the overseas supply chain management practice [J].Logistics technology,2012,(3):107-109.

[8] United Nations Conference on Silk Road Investment Guide [EB / OL]. (2009-09-16 ) [2014-5-15].

[9] British PetroleuGroup BP World Energy Statistics Yearbook [M] London:. Plattts, 2012.

[10] Kyrgyzstan Abdulla external force, Yang Zhaoping Russia and the Central Asian country's resources and the status of development of five potential analysis [J] Arid LandGeography, 2006,29(4): 588-597.

[11] Sun Hongling. Integrated supply chain. China material press .2002.1

[12] SrinivasanK, KekreS. Mukhopadhyay.Impactof electronicdata interchange technology On JITshipments [J] .Management Science.1994,40 ((10): 1291_1305

\section{Author Profile}

Jingjing Shi, female, Xidian University 2017 graduate student. Research: Supply Chain Management and Supply Chain Finance.
Address: Xidian University, Chang'an District of Xi'an in Shaanxi Province. Postcode: 710071, China

Jianze Zhou, male, Xidian University 2018 graduate student. Research: Business Administration. Address: Xidian University, Chang'an District of Xi'an in Shannxi Province. 